\title{
New insights into the Middle Eocene Climatic Optimum from lithium isotopes
}

\author{
ALEXANDER J. KRAUSE ${ }^{1}$, PHILIP A E POGGE VON \\ STRANDMANN $^{2}$, APPY SLUIJS ${ }^{3}$, ROBIN VAN DER \\ PLOEG $^{4}$ AND TIMOTHY M. LENTON ${ }^{5}$ \\ ${ }^{1} \mathrm{UCL}$ \\ ${ }^{2}$ JGU Mainz \\ ${ }^{3}$ Utrecht University \\ ${ }^{4}$ Shell \\ ${ }^{5}$ University of Exeter \\ Presenting Author: a.krause@ucl.ac.uk
}

The chemical weathering of silicate rocks is generally considered to be the primary control on the Earth's thermostat over long timescales, via the drawdown of atmospheric $\mathrm{CO}_{2}$ [1]. Perturbations to the carbon cycle in the past have been extensively explored, and some events, such as Oceanic Anoxic Events (OAEs) in the Cretaceous, are reasonably well understood in terms of their mechanisms and timing. However, the Middle Eocene Climatic Optimum (MECO), a $\sim 500$ kyr period of warming and elevated $\mathrm{CO}_{2}$ concentrations at $\sim 40 \mathrm{Ma}[2,3]$ exhibits different characteristics from other 'hyperthermal' events, suggesting different carbon cycle dynamics were in operation $[4,5]$.

We have obtained lithium isotope data from a suite of wellpreserved, carbonate-rich pelagic sediments across a number of Oceanic Drilling Program Sites. Lithium isotopes can be used as a tracer for silicate weathering as: continental clay formation preferentially takes up ${ }^{6} \mathrm{Li}$, leaving residual surface waters enriched in ${ }^{7} \mathrm{Li}$; and no fractionation is imparted by plant uptake [6]. Thus, $\mathrm{Li}$ isotopes are potentially a powerful tool for understanding $\mathrm{CO}_{2}$ drawdown, as the extent of continental clay formation can affect the transport of marine carbonate forming cations (e.g. $\mathrm{Ca}$ and $\mathrm{Mg}$ ).

Our Li isotope data exhibit a positive $\delta^{7} \mathrm{Li}$ excursion of $\sim 3 \%$, reproduced at the different sites. Alongside a previously published ${ }^{187} \mathrm{Os} /{ }^{188}$ Os record [5], we employ the use of the wellestablished Earth-system box model, COPSE [7] to explore changes to the carbon cycle and weathering during the MECO.

[1] Walker et al. (1981) J. Geophys. Res. 86, C10, 9776-9782. [2] Bohaty \& Zachos (2003) Geology 31, 1017. [3] Bijl et al. (2010) Science 330, 819-821. [4] Sluijs et al. (2013) Nat. Geosci. 6, 429-434. [5] van der Ploeg et al. (2018) Nat. Comms. 9:2877, 1-10. [6] Burton \& Vigier (2011) Handbook of Environmental Isotope Geochemistry (ed. Baskaran, M.), 41-59. [7] Lenton et al. (2018) Earth. Sci. Rev. 178, 1-28. 